\title{
Incorporating incomers and creating kinship in the Scottish
}

\section{Highlands}

\author{
By Kimberley Masson (University of Edinburgh)
}

This article challenges the common perception of Scottish kinship as a matter of clans and tartans by presenting relatedness in the Highland region as performative, processual, and incorporative. This involves a close look at the treatment of incomers and the language practices which appear to activate these forward-looking kinship patterns. The article is situated in - and about Highland houses where everyday kinship and language use is exemplified. The purpose of the paper is to encourage a rethink of Highland 'community' and the effects of historical migration while reiterating the centrality of kinship studies in anthropology.

\section{Introduction}

Kinship in the Scottish Highlands is popularly perceived as a matter of clans and ancestry, projected (mainly to tourists) by a romanticized iconography of tartans and history-celebrating gift shops. Yet, this image is challenged by a close look at everyday performative kinship and its significance over traced genealogy in today's Highland society. Having spent my childhood years in the Highlands, I recently became interested in looking at everyday processes of relatedness and belonging. The iconography of clans and tartans was something I had not encountered in Highland daily life. Such a notion has connotations of fixity - of 'belonging' as blood link - and little attention has been paid to incomers. This article problematizes the popular perception that English incomers are somehow peripheral to Highland belonging (as historical hostility and Scottish nationalist groups like 'Settler Watch' would have us believe). It is no longer sufficient to depend on historical accounts of descent and belonging: on the basis of my research, daily activity is so imbued with instances of 'doing' kinship rather than 'being' related that we would benefit much from studying Highland domestic and linguistic patterns. For my fieldwork ${ }^{1}$ - a summer spent around Ross-shire and Sutherland - I set out to uncover how people in this area actually go about their business of 'kinship' and 'belonging'. The people I met express their attitudes to these matters in an intricate dialectic: notions of relatedness and belonging oscillate between a selective forgetting of the past by 'locals' (a self-identification often meaning one or a combination of bloodlink, birthplace, and/or residence in the Highlands) and an active forward-looking incorporation of 'incomers' (particularly the English). Such a disposition towards the future is as evident, and as formative, as the claims to the past, a characteristic which most Scottish ethnography ignores due to a concern with distinctions and boundaries of

\footnotetext{
${ }^{1}$ This article is based on research in northern Scotland carried out in the summer of 2003 as part of the MA degree in Social Anthropology at the University of Edinburgh.
} 
exclusion (see Cohen 1986; Jedrej and Nuttall 1992). Much of Highland life is shaped by two-way migration: many young people leave the area for employment opportunities. Meanwhile, many families settle in the region for a sense of close 'community' and interrelatedness. Similar patterns are found elsewhere in the UK (see Edwards 2000). Inward migration to the Highlands has interesting implications for notions of 'kinship' and 'belonging', a central focus of this paper.

The material presented here comes directly from inside Highland homes. Stepping inside the house is a very literal boundary crossing, and integration into everyday life is presented here as a microcosm for integration into wider society. To clarify such boundaries of inside/outside and the dichotomy of forgetting/looking to the future, one need only consider the history of migration in and out of and around the Highlands. A genealogical perspective has become as tenuous as the inchoate future. Looking back highlights difference, yet people are searching for inclusion through claiming a shared present and future. Incomers to the region arguably strive for the same, and avoid any talk of their own history which would connote difference. By 'locals' and 'incomers' both forgetting the past - a sort of structural amnesia, a creative and positive forgetting they construct a togetherness that represents relatedness. My focus here is not on those dualistic markers of 'local' and 'incomer' that a concern with exclusion necessitates. Rather, I am concerned with scalar markers: various levels of localness whereby an individual might be considered as local through a blood link, or an incomer who stays becomes temporally 'local now', or a new incomer is perhaps considered a 'potential local'. This is something Phillips (1986) picks up on. Scalar markers are significant for what I found in the Highlands. Here, I do not suggest that incorporation and 'fictive kinship' replaces genealogical information. Instead, in this particular context, the two work in an interesting dialectic, perhaps somewhat comparable with Marilyn Strathern's notion of 'eclipsing' (1988), whereby elements are temporally and contextually concealed and revealed. Indeed, Phillips suggests (for Yorkshire) that:

\begin{abstract}
...the characters, or stereotypic markers, for expressing the idea of a cultural boundary are not fixed in their meaning. Rather, the boundary is flexible; and this is so because the markers whereby local identity is symbolised are several, and their significance varies in and through time depending on the context of social interaction. (Phillips 1986:141)
\end{abstract}

Whenever I hear someone in the Highlands exclaim 'it's all happening here!', I think of the processes of performativity, incorporation, belonging, and becoming. In people's homes it is often apparent that a schematic use of language represents the way various relationships evolve in the domestic arena. I suggest that the relationship between language and houses is both formative of and symbolic of the Highland way of living. The use of language in a kinship context has much to do with the reconsideration of selfhood and the positive encounter with 'otherness' through incomers. Here, I establish that the prospective direction of relatedness eases the incorporation of incomers into the society through metaphors within the local kinship system. I am also concerned, on one level, with kinship in its idiomatic state of explaining how people in the Highlands understand 'belonging' and how migration affects the relationships enmeshed in that understanding. Not only does this encourage a rethink of the Highlands in a shift away from a romanticized popular perception, it reiterates the centrality of kinship practices to wider social concerns. 


\section{Practice makes perfect: metaphors and the creation of similarity}

I met various individuals who had scarce knowledge of their ancestry but a keen interest in 'new arrivals'. 'Locals' were always on hand to help those 'incomers' (who chose to settle) fit in. Welcoming these individuals into one's home, and the use of certain rooms in specific ways, particularly demonstrates the art of 'fitting in' and creating a comfortable space, as I show below. The incorporation of incomers is often notable in a more ritual setting such as the patient teaching of ceilid $h^{2}$ dance steps: the interaction is sometimes an intoxicated and humorous one, but more than this, it is a project of inclusion, an example of 'belonging' through practice made perfect. In a different context, David McCrone comments that the Highlands are peripheral to Scotland; to progress, people in the Highlands must 'set aside tradition' and move towards creation (2001:68). I suggest that we meet this Highland periphery most clearly in the everyday context: if Scottish culture is 'characterised as split, divided, and deformed' (ibid:129), then the marginal Highland society is external enough to create its own solidarity through progressive practices.

The everyday activities I encountered were forward-looking and processual and the local interest was in 'new blood' of two kinds: first, literally, the kind brought with the birth of children and secondly, metaphorically, as the fresh perspective of community brought by incomers. Simultaneously, securing a place in the society involves knowing the metaphors of belonging. Such 'belonging' can also be learned and I often felt I was encountering a constant incorporation of incomers. A certain use of metaphor brings 'locals' and 'incomers' closer together. Those who are 'rooted' by traced genealogy are sufficiently integrated and can move in and between houses easily. Individuals requiring a route into Highland society appear to learn some sort of language skill that potentially incorporates them into this way of doing kinship. When, for instance, one hears 'Come in! Through here to the kitchen...', the immediate association might be with a distance from the house's intimacy, being led past the living room to the back of the house, which is not truly the case. But this example is, I suggest, something of a speech corridor: the recitation of arrival actualizes the process, before bodies materialize the process by physically arriving inside the house. This use of language is something of a schematic technique: in speaking this way, Highland people demonstrate an awareness of social incorporation through the house. An elderly woman encouraging those around her to act in a lively manner, 'because silence would make everything stop', also demonstrates the significance of performativity. Allegorically, the meaning here is denotive of Highlanders' perception of social relations. The recipient of such commands is being encouraged to stay, and to do the things that Highland people themselves do. Knowing how to respond to these instructions, or indeed to make the commands, necessitates a certain linguistic skill which can be both tacitly understood (that is, by those with links to the community) or made perfect by practice (that is, by incomers).

A most incorporative example of metaphor use is by an engaged couple, the man local and his fiancée an incomer. By meticulously learning the local idioms and even trying to master the dialect, the young woman secures her place not by marrying in but by learning the rules of the game. This active becoming depended on the local's ability to externalize

${ }^{2}$ Ceilidh is a Scottish (and Irish) social gathering with traditional music, dancing, and recitals. 
part of what Bourdieu (1990) would call the 'habitus': those unconscious but systematic actions that arguably orient what it is to be 'Highland'. In turn, an incomer might use the metaphor of 'falling in love' with the place (Jedrej and Nuttall 1992:131). Is it, then, enough to talk one's way in? In my fieldwork, I sensed that this relationship with place and people had to be acted-out. The idea of habitus also links well with the idea that knowledge is both technological and tacit: there may not be an understanding of why something is acted-out, but there is a tacit understanding that it should be and performing according to this is a way of incorporation (see also Antze and Lambek 2003). Actions and words seem to speak as loudly as each other. Take, for instance, the wedding of a local man and his incomer bride. Together, they hold the meyne-cog (a wooden vessel containing all sorts of alcohol mixed with eggs). The bride and groom drink from it in a fertility ritual which is apparently only successful if the meyne-cog travels in a clockwise direction and every guest takes some of the liquid. At the same time as incorporating an incomer and sealing the marriage, the ritual creates a kind of commensality for all who partake. The father of the bride will perhaps make a speech where friends come to be included in the references of the word 'family' and thanked for their presence. This is an example of an innovative way of creating kinship. Individuals place more or less emphasis on each way of defining 'belonging' depending on context. At once, we encounter the genealogical and the performative.

\section{Highland history and processes of 'forgetting' and 'finding' kinship}

The intricate interplay of 'genealogical' and 'performative', of 'forgetting' and 'finding' kinship is linked to historical migration in the area. Highland Scotland is a heterogeneous region. Mass migration following the nineteenth century Highland Clearances has left a trickle of social effects: the constant flow of people has meant that kinship is fluid and priority is given to performative kinship in everyday life. Genealogical information from the past has virtually disappeared through constant population mobility. Individuals I met traced kinship to the grandparental or parental generation but rarely further: they were not concerned with kinship information of the past, finding it neither formative nor influential.

The nineteenth-century Highland Clearances ${ }^{3}$ saw families forcibly removed from their crofts. Those factors which had defined kinship - shared blood and alliance with supporter clans - were rendered impossible in a disconnected nation (see Devine 1994). A change in naming practices demonstrates the extent of kinship upheaval. Records show that fixed singular surnames - such as Mac-Domnhail (MacDonald, literally 'son of Donald') - began to appear. Previously, clansmen could have traced ancestry through their own 'genealogical' first name set - for example, Alistair mac-Tamhas mac-Eoin mac-Angus (Alistair, son of Thomas, son of John, son of Angus) could recognize Angus as his great-grandfather. The new system meant that the parental generation was the furthest temporal point to which most people were able to trace their ancestry, but individuals with the same surname could trace their 'horizontal' links. The flux between

\footnotetext{
3 'Highland Clearances' is the term used to describe extensive and direct removal of peasant communities, mostly from Sutherland and Caithness, to make way for big sheep farms (for a comprehensive account see Devine 2000).
} 
'knowing' and 'unknowing' kinship information at this time has arguably had a trickle effect onto the kinship practices we encounter in the region today. Current (whether genealogically 'horizontal' or non-genealogical) relationships can be acted-out and constitutive of one's place in this society. The upheaval of the Clearances is in the past, but the migration remains and an adaptable way of rendering kinship is perhaps a positive legacy of the Highland Clearances, enabling as it does more social inclusion.

\section{Descended from whom? Ancestors, children or no-one at all?}

The constant animated activity in Highland houses - visiting, chatting, encouraging children to sing loudly, moving around rooms - represents the enjoyment of acted-out relationships. Photographs of ancestors hang on walls, but remain largely unidentified and rather insignificant. The people were described to me as being 'well up the tree': their place on the wall is almost decorative (as one woman commented: 'Oh, I just put it there, I'm not sure of their names...'). Owners of these photographs told me they know they are 'descended from someone'. This would exclude incomers, who in the Highland ancestral context are descended from no-one recognizable. Incomers do not have the anecdotes and 'passed-down' information that popularly characterizes life in the Highlands. Without a 'linking' relative to help situate newcomers, it might be difficult to find a place in the 'community'. However, the locals I knew appear to have little concern for identifying the ancestors. I do not suggest that genealogy has completely lost significance or been replaced, but rather that more focus is placed upon acted-out associations in the present. This is a good example of the 'eclipsing' idea. Rummaging around the genealogical past is often portrayed by those living in this region as an event for tourists, or as a hobby for the elderly and the anthropologist: it is not, for most, constitutive of relatedness or of the self.

The scene of much kinship activity, the house, is treated not as a setting or as a structure, but as part of the happenings. Often named, the house can be imagined as just as animated as the inhabitants: metaphors suggest that it could see and speak of the activities it hosts. These metaphors are particularly employed when families move out of the house: 'how can it be bricks and mortar when it has seen all of this?' was one question that symbolized linkages between personhood and locality. The view that by building a house 'you place it there, you move in, everything that happens you have created' suggests that incomers could just as easily stake a claim to Highland living: creating a house is like creating a child. A reference point for future performativity is constructed. One requires no documentation of Highland descent in order to move in, buy land, and to settle. Having done so, a 'route' turns into a 'root' for future generations. Simultaneously, by performing incorporative practices such as marrying-in and producing children, an incomer becomes 'descended' from his or her children.

\section{Speaking in structures: incorporating incomers}

What is it about the house that allows it to convey what words will not or cannot say? Anthropologists have already documented that the structure is often represented as an animate object: with 'eyes' and a 'mouth' (Carsten and Hugh-Jones 1995:2-3), it - like 
people - contains the key to culture. Indeed, with human features and occasionally a name, we often hear the house spoken of in a familial metaphor. For instance, when an old man returned home after a short break, he patted the doorframe and laughed 'that's us home, lass', addressing the structure by a diminutive term normally reserved for young women. I was told this by one of his relatives, and thought it was exceptional. However, with the story in mind, I became more aware of houses and saw many addresses where houses were named like females ('Clare', 'Asleigh', and 'Beverley' to name a few). It is important to point out that this metaphor is an example of Highland people perceiving the house as schematic: it is part of the way they interact with people, both their old friends and with incomers.

The house also represents, in the Lévi-Straussian sense, the way society operates. For example, when an incomer is invited into the heart of the home, it could be argued that this is his welcome into the heart of the society. The daily activities of life that constitute social relationships in the Highlands occur inside houses so that the house is perceived as part of the process. For instance, I entered numerous kitchens in Highland houses where the range was flanked by an oversized dining table and a large sofa - and the external back door led directly in here, bringing outsiders directly into this central area of family life. I suggest that this closeness to the outside does not make the kitchen a 'staging area' for guests but, more interestingly, demonstrates that Highland people are eager that individuals feel 'settled in', welcomed, and part of the activity. On a couple of occasions, I noticed kitchens had more teapots and cafétières displayed than one family could need: this seems to point to a special kind of hospitality, as if the utensils are lined up just waiting to draw more people into the centre of kinship activity. Meanwhile, corridors of formal living rooms, dining rooms, and sitting rooms are rarely used, and therefore arguably these are staging areas: afternoon tea served formally in the living room has none of the effects of drinking coffee while sitting on the kitchen sofa. Such formality is reserved for the minister, the doctor, or the undertaker: people who live in the same way in everyday life and in the vicinity are perceived as inextricably involved and are incorporated accordingly. This arrangement is likely to be widespread in the UK. The kitchen is where many kinship functions occur at once for both families and their guests: I have experienced little distinction between the two. Often popularly perceived as the 'heart' of the house and family, it was not 'out of limits' to visitors: they were encouraged to participate in the everyday closeness of family life. I follow Webb Keane (1995) in suggesting that the house can provide the key to a culture, and be read as the dictionary of that culture.

\section{Doors: the content of a boundary}

Physical boundaries, such as doors, also indicate the social processes that occur in houses. Often, arriving at the front door, you might be told 'you should've gone round the back!', the implication being that the front door is either for the most formal uses or for the most banal. In everyday life, many Highland houses are entered by the back door, and it is on the threshold of the open back door that people will pause to chat. I seldom saw people chatting at the front door and most of those who come to the front door - the postman, milkman, and paperboy - leave without the door opening. So the back door, which opens directly into the kitchen, the creative heart of the home, is therefore part of 
the creation and elaboration of social relationships. It is saturated with agency. While the front door is about formal social structure, the back door is about more informal or emotional structures. The front door threshold is an interesting one and marks the anticipation of Highland living: the border is transient. One either arrives and turns away immediately - like the postman each morning - or one steps right in. This careful working of metaphor - both linguistically as the words represent other social meanings and structurally when the threshold actually involves a whole set of social rules - is the measure of which incomer is accepted and which must remain outside. Individuals like the doctor and the minister are, of course, already 'insiders' but their professional capacity detaches them. I have seen a doctor arrive at the front door to treat a patient, who was also his friend. At the weekend, the same doctor would enter the same house by the back door, to collect his friend for a round of golf. Journeys into the society evidently begin with journeys over boundaries. However, with a constant flow of people in, out, and around the region, boundaries become fluid and the way people move, particularly around houses, demonstrates this.

\section{Houses of fluid boundaries}

When a new site for houses was planned, groups of friends I knew reserved homes to secure living in the vicinity of each other. It is described as 'easier' to live this way, 'where it's all happening, really'. This encourages me to think that the kinship processes centred inside the house have fluid boundaries, and that they could easily spill over into interactions with the neighbours: 'It's happening'. Even this use of the continuous present tense points to processual kinship that is forward moving in its temporal direction. It seems that new houses huddle together despite, or perhaps because of, the open landscape around them, and dissolve distinctions between 'local' and 'incomer'. As Joëlle Bahloul has demonstrated,

the boundaries of the domestic group are not simply genealogical; the group also includes relationships of neighbourhood, friendship, and personal affinity which have been incorporated into it simply because they evolve in the domestic world. (Bahloul 1996:51)

This fits well with what I encountered: people who are living together and experiencing the same things, have a close bond (see also Waldren 1996) and create new ways of 'belonging'.

\section{Conclusion}

I have been struck by the idea that 'the local-outsider dichotomy does not so much identify categories of person as indicate types of agency, the way things are done rather than who does them' (Jedrej and Nuttall 1992:180). I reiterate here my focus on different markers of belonging and becoming. It seems that Jedrej and Nuttall's concern with exclusion necessitates dualistic markers. In my research, 'inclusion' has, by the same rule, necessitated scalar markers. It follows that the differentiation of people in the Highlands is not easily identifiable: I had to be informed about who was a newcomer and who was local (it transpired much of the time that the locals were also incomers of sorts), 
and my only clear indicator was dialect. When I asked why Highland people were willing to accept the influx of newcomers, I found that (like newborn children) they are attributed the complimentary (but in their case figurative) 'new blood' label. This goes some way in demonstrating the significance of reconsidering agency in Highland society. The everchanging dynamics of the group through demographic mobility are responsible for this situation, and attitudes suggest that such change is useful, providing as it does the potential for new social relationships. I have demonstrated that the performatory aspects of language use in the Highlands, such as the talk surrounding processes of entering the house, are useful in explaining one level of Highland hospitality. And yet the same processes can be analysed in a denotive form: they actively incorporate incomers. Giving individuals a physical space within this domestic structure is metonymic of giving them a place in society. This is how I encountered the Highland house - language practices inside it and about it offered me a very significant insight into the society. This should encourage a rethink of the effects of migration, of how 'belonging' is constructed, and the relevance of kinship in the question of 'community'.

\section{References}

Antze, P. and M. Lambek. 2003. Tense Past. London: Routledge.

Bahloul, J. 1996. The Architecture of Memory: A Jewish-Muslim Household in Colonial Algeria 1937-1962. Cambridge: Cambridge University Press.

Bourdieu, P. 1990. The Logic of Practice. Oxford: Polity.

Carsten, J. and S. Hugh-Jones (eds). 1995. About the House. Cambridge: Cambridge University Press.

Cohen, A.P. 1986. Symbolising Boundaries: Identity and Diversity in British Cultures. Manchester: Manchester University Press.

Devine, T.M. 1994. Clanship to Crofters' War: The Social Transformation of the Scottish Highlands. Manchester: Manchester University Press. 2000. The Scottish Nation 1700-2000. London: Penguin.

Edwards, J. 2000. Born and Bred. Oxford: Oxford University Press.

Jedrej, C. and M. Nuttall. 1992. White Settlers: The Impact of Rural Repopulation in Scotland. Luxembourg: Harwood Academic Press.

Keane, W. 1995. The spoken house: text, act, and object in eastern Indonesia. American Ethnologist. 22, 102-124.

McCrone, D. 2001. Understanding Scotland: The Sociology of a Nation, 2nd edition. London: Routledge.

Phillips, S. 1986. Natives and incomers: the symbolism of belonging in Muker parish, North Yorkshire. In Symbolising Boundaries: Identity and Diversity in British Cultures (ed) A.P. Cohen. Manchester: Manchester University Press.

Strathern, M. 1988. The Gender of the Gift. Berkeley: University of California Press. 
Waldren, J. 1996. Insiders and Outsiders: Paradise and Reality in Mallorca. Oxford: Berghahn Books.

\section{Acknowledgements}

I thank Janet Carsten for her guidance, Charles Jedrej for his meticulous comments, and Michael Rosie for his enthusiastic support.

\section{About the author}

Kimberley Masson is a postgraduate in anthropology at the University of Edinburgh. The kinship and belonging ideas presented here form the backdrop of her PhD. Current research is on experiences of fertility decisions and the wider context of fertility decline in Scotland. Contact K.A.Masson@sms.ed.ac.uk 